\title{
The influence of climate change on flood risks in France - first estimates and uncertainty analysis
}

\author{
P. Dumas ${ }^{1,2}$, S. Hallegatte ${ }^{1,3}$, P. Quintana-Seguí ${ }^{4}$, and E. Martin ${ }^{5}$ \\ ${ }^{1}$ Centre International de Recherche sur l'Environnement et le Développement, Campus du Jardin Tropical, 45 bis, \\ Avenue de la Belle Gabrielle, 94736 Nogent-sur-Marne Cedex, France \\ ${ }^{2}$ Centre de Coopération Internationale en Recherche Agronomique pour le Développement, Avenue Agropolis, \\ 34398 Montpellier Cedex 5, France \\ ${ }^{3}$ École Nationale de la Météorologie, 42, avenue Coriolis, 31057, Toulouse, France \\ ${ }^{4}$ Observatori de l'Ebre (URL - CSIC), Horta Alta 38, 43520 Roquetes (Tarragona), Spain \\ ${ }^{5}$ CNRM-GAME, UMR3589 (Météo-France, CNRS) 42, avenue Coriolis, 31057, Toulouse, France
}

Correspondence to: P. Dumas (dumas@ centre-cired.fr)

Received: 30 January 2012 - Published in Nat. Hazards Earth Syst. Sci. Discuss.:

Revised: 15 November 2012 - Accepted: 26 November 2012 - Published: 27 March 2013

\begin{abstract}
This paper proposes a methodology to project the possible evolution of river flood damages due to climate change, and applies it to mainland France. Its main contributions are (i) to demonstrate a methodology to investigate the full causal chain from global climate change to local economic flood losses; (ii) to show that future flood losses may change in a very significant manner over France; (iii) to show that a very large uncertainty arises from the climate downscaling technique, since two techniques with comparable skills at reproducing reference river flows give very different estimates of future flows, and thus of future local losses. The main conclusion is thus that estimating future flood losses is still out of reach, especially at local scale, but that future national-scale losses may change significantly over this century, requiring policy changes in terms of risk management and land-use planning.
\end{abstract}

\section{Introduction}

River floods have caused increasing damages in Europe in the last decades, and it is widely accepted that almost all of this increase has been due to changes in flood exposure, i.e. in the population and assets that are located in flood-prone areas (Barredo, 2009). In particular, the impact of climate change on floods cannot be identified in flood loss time series. But it does not mean that anthropogenic climate change will not affect flood losses in the future, as global mean temperature increases and local climate patterns are affected.

Indeed, flood frequency and intensity are determined by the timing and intensity of precipitations, as well as the state of water storages (soil, lakes and reservoirs). Climate change will lead to modifications in these flood drivers (Planton et al., 2008), and is thus likely to affect flood characteristics and resulting economic losses.

Assessing how climate change may affect floods in the future is important for several reasons. First, local planners make decisions that have a long term impact on flood vulnerability. New urban development can, for instance, increase the population and assets located in flood-prone areas for decades. This is why planners need to include information on future floods locations, frequency, intensity and costs, to anticipate and adapt to these changes. Also, information on how future flood losses are likely to evolve is useful to assess the robustness of the current French flood insurance system, which is based on a public-private partnership with government guarantee. A large increase in average losses would require an adjustment of the insurance system, or the implementation of ambitious adaptation measures to prevent it. Such measures take a long time to make a difference, and would require anticipation, and thus information on future flood characteristics.

Yet, the assessment of future changes in flood losses is a difficult task, because of many uncertainties. First, floods are 
extreme events, and evidence and observations are scarce, especially on the most extremes floods that are also the rarest. It makes it more difficult to apply statistical methods, calibrate and validate models. Second, there is an uncertainty on future emissions of greenhouse gases, which translates into an uncertainty on the intensity of future global climate change. And most importantly, there is a large uncertainty on climate change itself. Global climate models project different climate change patterns, especially for precipitations. Downscaling techniques are needed to transform low resolution model outputs into the high resolution scenarios that are needed to investigate flood risks. But these downscaling techniques do not give the same results. Also, hydrological models that translate precipitation into river flows are imperfect, and add another layer of uncertainty, especially in ungauged basins.

Finally, economic data are unavailable or imperfect, making the link between river flows and flood economic losses highly uncertain. Past flood losses are influenced by natural variability and socio-economic trends, making it difficult to calibrate models. And economic valuation is made even more difficult by uncertainty on future changes in vulnerability and on future adaptation to climate change, and by valuation problems and ethical issues (e.g. concerning the discount rate or the valuation of life and ecosystems).

In this paper, we build upon Quintana Seguí et al. (2011) and propose a simple methodology to project possible evolution of river flood damages over mainland France. The aim and the methodology used are similar to the recent studies of te Linde et al. (2011) for the Rhine river and Feyen et al. (2012) over Europe. Our main objectives are to assess the likelihood of major changes in flood losses in France, and to assess the uncertainty in flood projections. Using only one emission scenario, one climate model, and one hydrological model, we do not investigate the full uncertainty. Only the uncertainty arising from the downscaling step and the economic analysis is investigated.

Also, we assume that populations and assets remain unchanged along this century (Feyen et al., 2012). We thus investigate the impact of climate change in the current demographic and socio-economic context, without taking into account aggravating trends (e.g. the current migrations toward more flood-prone regions of the country such as LanguedocRoussillon) or mitigating trends (e.g. increasingly strict landuse policies, potential adaptation measures). This limitation is not a problem, as we do not claim to predict future flood losses, but to provide information useful to help decisionmakers manage climate change and natural risks. Identifying possible outcomes regarding whether and where future flood risks would become unacceptable in the current socio-economic context and in absence of adaptation measure could indeed be a helpful input in the design of adaptation and risk management policies.

The main contributions of this study are (i) to demonstrate a methodology to investigate the full causal chain from global climate change to local economic flood losses; (ii) to show that future flood losses may increase in a very significant manner in France, with increases ranging from 100 to $230 \%$ in 2050 in this study; (iii) to show that a very large uncertainty arises from the downscaling technique, since two techniques with comparable skills at reproducing reference river flows give very different estimates of future flows, and thus of future losses. The main conclusion is thus that current knowledge does not allow for a robust estimate of future flood losses, especially at local scale, but that future national-scale losses may increase very rapidly over this century, requiring policy changes in terms of risk management and land-use policies.

\section{Methods and data}

Changes in flood hazards risk under climate change is the focus of several studies, such as Kleinen and Petschel-Held (2007) who investigate flood frequencies change at the global level. Also, Prudhomme and Davies (2009a,b) assess river flow changes on different basins over the UK, with a focus on uncertainties. They find that the uncertainty arising from the global climate model is more important than downscaling uncertainty, which in turn is more important than the uncertainty from hydrological modeling. Quintana Seguí et al. (2011) study the change in flood extremes and assess the uncertainty on extremes for three downscaling techniques. Their analysis serves as the basis of the present study.

Our methodology is based on two steps. First, we carry out a statistical analysis based on the extreme value theory using a Gumbel distribution to assess how the 10-yr and 100-yr river flows change in scenarios with climate change.

Then, the assessment of economic costs is based on the selection of a reference event, here the 100 -yr event. It is assumed that all floods with return periods shorter than 100yr (i.e., smaller floods) do not cause any loss, and that all floods with return periods longer than 100-yr cause the same losses as the 100-yr event. Then, it is assumed that the change in flood losses can be modeled as a change in the frequency of the reference event, with no change in intensity.

This section explains in details this methodology, and its limitations.

\subsection{Climatic and hydrological data and scenarios}

The scenarios used in this study are the same as in Quintana Seguí et al. $(2010,2011)$. They were created using a top-to-bottom approach: they were derived from a single climate simulation with a single greenhouse gas emission scenario, which was statistically downscaled using two different methods and then was used to force a single hydrological model. This setting makes it impossible to assess the full uncertainty in future flood losses; only the uncertainty arising from the downscaling step can be investigated. 


\subsubsection{Climate model}

The climate simulation used in this study was developed by Somot et al. (2008) using SAMM (Sea Atmosphere Mediterranean Model). This model is the result of coupling the atmospheric model ARPEGE-Climate (Gibelin and Déqué, 2003) and OPAMED (Somot et al., 2006), a model of the Mediterranean Sea. ARPEGE covers the whole globe, but its resolution is variable. Its pole of maximum resolution $(50 \mathrm{~km})$ is situated on the Mediterranean Sea. OPAMED's resolution is about $10 \mathrm{~km}$.

For the 21 st century, the simulation was carried out using the IPCC SRES A2 emission scenario (Nakićenović and Swart, 2000), which assumes a large increase in greenhouse gas emissions along the 21 st century. In the climate simulation, temperature increases in France by between 2 and $3{ }^{\circ} \mathrm{C}$ in winter and by between 3 and $6^{\circ} \mathrm{C}$ in summer. Precipitations increase in winter in the north (by 0.2 to $0.5 \mathrm{~mm} \mathrm{~d}^{-1}$ ) and decrease in the south (by up to $0.5 \mathrm{~mm} \mathrm{~d}^{-1}$ ). In summer, precipitation decreases over all of France by up to $1 \mathrm{~mm} \mathrm{~d}^{-1}$.

\subsubsection{Gridded dataset of weather observations}

The statistical downscaling techniques were trained and validated using a gridded database of weather observations. The SAFRAN/F database (Quintana-Seguí et al., 2008; Vidal et al., 2010) was created using SAFRAN (Durand et al., 1993), which is a meteorological analysis system that produces hourly analyses of near-surface atmospheric parameters. In the case of SAFRAN/F the inputs are the observations from the automatic, synoptic and climatological networks of Météo-France and a first guess. The first guess corresponds to the output from a large-scale operational weather prediction model. The resulting database has a spatial resolution of $8 \mathrm{~km}$. In this paper the SAFRAN/F weather data will be referred as SF.

\subsubsection{Statistical climate downscaling techniques}

The description of the methods of downscaling will be short, as they are explained in more detail in Quintana Seguí et al. (2010).

The quantile mapping technique (QM) (Déqué, 2007; Wood et al., 2004) corrects the distribution function of model outputs. In the training period, for each point of SF's grid, the time series of SF and the nearest grid point of the climate simulation are compared in order to find a correction for each percentile of the climate simulation. Then, the same corrections are applied to the climate simulation data in the downscaled period. The correction is applied to each variable separately and is calculated for each season. Therefore, it is assumed that the climate model rightly simulates to which percentile each value belongs, but is not able to determine the value associated to each percentile, which is taken from the observed distribution.
The weather typing (WT) approach used in this study (Boé et al., 2006; Boé and Terray, 2008; Pagé et al., 2009) is based on weather typing and conditional resampling. Two largescale predictors are used: sea level pressure (SLP) and surface temperature. First, a limited number of weather types discriminating for precipitation in France are extracted as in Boé and Terray (2008). Each season is processed independently and between 8 and 9 weather types are obtained. Then each day " $D$ " of a climate projection is downscaled in accordance with its SLP and surface temperature. In the learning period, a day " $\mathrm{D}$ " " belonging to the same weather type as day " $D$ " with the most similar precipitation and temperature indices is selected and its corresponding SF data are used.

It must be noted that the two methods have different behaviours in case of precipitation events outside the present distribution. The QM method correction functions are extrapolated above the present day maximum, hence downscaled precipitation events above the present maximum are possible if they are present in the future climate run. On the contrary, the WT method rely only on the SF database of analysed precipitation. The method cannot produce daily precipitation events higher than those present in the historical data. This is a serious limitation of the method that tends to underestimate high precipitation events. However, this method is able to produce increased flood frequency by selecting more often the highest precipitation events of the historical database. The bias on the results associated with WT is impossible to quantify, especially with respect to the other uncertainties associated to the method.

\subsubsection{Hydrological model}

The hydrological simulations performed in this study were carried out with the SAFRAN-ISBA-MODCOU (SIM) model, which simulates energy and water balances and their associated river discharges over all of France (Habets et al., 2008; Quintana Seguí et al., 2009). The soil-vegetationatmosphere transfer scheme ISBA (Noilhan and Mahfouf, 1996; Noilhan and Planton, 1989; Boone et al., 1999) is at the core of the system. ISBA calculates all the energy and water fluxes between the Earth's surface and the atmosphere. ISBA is coupled with the hydrogeological model MODCOU (Ledoux et al., 1989) through the surface and subsurface runoff. MODCOU routes these two fluxes to the river and within the river. MODCOU also simulates the underground water in the Seine and Rhone basins. ISBA is run at a resolution of $8 \mathrm{~km}$ (the same as SF). The spatial resolution of MODCOU is variable. MODCOU calculates river discharges over more than 900 points. SIM was forced by SAFRAN/F to produce a control run from observed weather data, and by downscaled model output to produce the hydrological scenarios.

SIM is run using hourly data from SAFRAN/F and produces simulated discharge at a 3-hourly time step. However, due to difficulties to obtain accurate precipitation at time 
scale smaller than one day, only daily data are analysed in this study. Flood events, such as flash floods, with a characteristic time scale of a few hours are only assessed through their impact on the daily mean of the discharge.

\subsubsection{Hydrological scenarios}

Three hydrological scenarios have been produced: (1) a reference scenario (referred to as "SFS") is calculated by SIM model from climate observation SF; (2) two climate change scenarios (from 1961 to 2100) calculated by SIM from the two downscaled climate change scenarios (QM and WT) (these two hydrological scenarios are referred to as "QMS" and "WTS"). These have already been studied in (Quintana Seguí et al., 2010, 2011).

Quintana Seguí et al. (2010) showed that the different downscaling methods produce similar long term annual averages in terms of temperature and precipitation changes. But there are important differences in terms of spatial patterns and seasonal distribution of the changes. Therefore, the uncertainties in the mean precipitation and temperature obtained after downscaling a climate simulation are relevant.

The differences in the atmospheric variables are propagated through and amplified by the hydrological model when producing the hydrological scenarios QMS and WTS. For example, in some basins, for some seasons, the QMS and WTS scenarios do not agree on the sign of the flow anomaly; and in basins in which the methods agree in the sign, there are sometimes differences of up to $30 \%$ in the intensity of the flow anomaly.

Nevertheless, some geographical and seasonal patterns emerge. In the Mediterranean France, a decrease in the average discharge at the middle of the century is expected in most of the stations for most of the year. Only some locations exhibit increases in winter (and more rarely in spring). Annual discharges may increase in some stations located near the Massif Central. There is more agreement in winter and summer than in autumn and spring. The anomalies are more significant in summer.

Relating to extremes, which are the subject of this paper, Quintana Seguí et al. (2011) showed that both downscaling methods (QM and WT) were able to reproduce the observed extremes of high precipitation, improving the performance of the climate model.

\subsection{Current return levels and changes in flood return periods}

To determine the return level and return period changes, the extreme value theory is used. A Gumbel distribution is fitted on the flow time series using maximum likelihood, using the $\mathrm{R}$ packages ismev and extRemes (Stephenson and Gilleland, 2005; Katz et al., 2002). The maximum likelihood method also allows to determine confidence intervals on the resulting return levels. In addition to the Gumbel distribution, the
Generalized Extreme Value distribution is also used, which is a generalization of the Gumbel distribution. The knowledge of the distribution allows the determination of either return levels for a given return period, or return periods (probabilities) associated to a given level. As the time intervals we use are all below 40-yr, return levels corresponding to the 100-yr event are subject to considerable uncertainty.

\subsection{Economic assessment of flood losses}

Starting from a classical formalization of expected flood damages, several simplifications are applied to come up with a simple evaluation of future damage changes due to climate change.

All calculations are carried out over small hydrological units, the "sous-secteurs hydrographiques" (sub-catchment basins, hereafter "SSH"), from the the French hydrographic database, more precisely the SANDRE referential in the BD CarTHAgE (MEDD and IGN, 2009). ${ }^{1}$

\subsubsection{Methodology}

Expected flood damages at a given location (i.e., in one SSH) at a given point in time can be modeled as:

$\int p(F) c(F) d F$,

where $F$ is the river flow, $p(F)$ the probability of flow $F$, $c(F)$ the cost of the floods caused by the flow $F$, taking into account existing protections, economic valuations, and possibly including discounting. The cost should be different from zero for extreme values of $F$ only, when the flow leads to floods.

A first simplification is done by considering that over a given time period the climate is stationary, and by taking into account only annual maxima, which allows the use of extreme value theory and to consider that the maximum flow probability density is described by a GEV distribution; here we use classically a Gumbel distribution (Katz et al., 2002; te Linde et al., 2011; Feyen et al., 2012). Taking annual maxima amounts to considering that there is only one damaging flood each year over one SSH, which is acceptable considering the size of these areas.

Over the time period (e.g. a 40-yr window), expected damages in one SSH becomes:

$\int p\left(F^{\mathrm{M}}\right) c\left(F^{\mathrm{M}}\right) \mathrm{d} F^{\mathrm{M}}$,

where $F^{\mathrm{M}}=\max _{d \in \mathrm{Y}} F(d)$ is the maximal annual flow, and $p\left(F^{\mathrm{M}}\right)$ is the probability of exceeding this flow at least once

\footnotetext{
${ }^{1}$ MEDD: Ministère de l'Ecologie, du Développement durable, des Transports et du Logement. IGN: Institut Géographique National.
} 
in a year, and follows a Gumbel or a GEV distribution. Considering two periods (current and future), and using a hat for the future period, climate change costs are given by:

$$
\begin{aligned}
& \int \hat{p}_{\mathrm{CC}}\left(F^{\mathrm{M}}\right) \hat{c}_{\mathrm{CC}}\left(F^{\mathrm{M}}\right) d F^{\mathrm{M}} \\
& -\int \hat{p}_{\text {bas }}\left(F^{\mathrm{M}}\right) \hat{c}_{\text {bas }}\left(F^{\mathrm{M}}\right) d F^{\mathrm{M}},
\end{aligned}
$$

where "bas" is a counter-factual baseline without climate change, and "CC" is a scenario with climate change. Ideally, both $\hat{c}_{\text {bas }}$ and $\hat{c}_{\mathrm{CC}}$ should take into account future economic development, protections and activity location changes (including adaptation policies).

In this analysis, however, we assume that costs of future floods are the same as current floods, for a given flood, with and without climate change, $\hat{c}_{\text {bas }} \equiv \hat{c}_{\mathrm{CC}}$. These hypotheses amount to ignoring future socio-economic changes and adaptation to climate change. We thus estimate the impact of climate change on the current population and on current assets.

The baseline climate is considered to be a continuation of the current climate, assumed stationary. The probability of future floods without climate change is thus the same as the probability of floods over the 1961-2007 period.

Taking into account all those simplifications, the expected annual flood cost in one SSH becomes:

$\int\left[\hat{p}_{\mathrm{CC}}\left(F^{\mathrm{M}}\right)-p\left(F^{\mathrm{M}}\right)\right] c\left(F^{\mathrm{M}}\right) d F^{\mathrm{M}}$.

Assessing current flood damages over the whole French territory for all the possible flood levels is still a very difficult task, especially because damages for different flood levels are not easily available. Only a handful of events are precisely described, in most cases big events.

To circumvent this difficulty, we assume that only two events are possible: either there is no flood (and no damage) or there is a flood, which is modeled as a unique "representative flood." Damages associated to that flood are considered to be the upper limit for flood damages at a given location (i.e., in a given $\mathrm{SSH}$ ), while damages associated with smaller events are considered to be negligible.

This amounts to considering that there is a flood protection (a dike, for example) calibrated for this event, such that no damage occurs for lower river flows, and that this protection is of no use if the flow gets higher. Implicitly, we consider that the water extends rapidly over the low lying flood plains as soon as river water levels exceed the protection height as in Feyen et al. (2012), or that the protection collapses.

Considering that the representative event is the upper limit for flood damages leads to the neglect of the fact that rarer events should lead to higher water depth and larger inundated areas, a simplification that is also done in te Linde et al. (2011), while Feyen et al. (2012) take into account the whole distribution.

Noting $T$ the reference return period associated with the representative flood and $F_{T}$ the corresponding flow, the defi- nition of the return period is:

$p_{\left(F^{\left.\mathrm{M}_{\geq} F_{T}\right)}\right.}=\frac{1}{T}$.

The hypothesis stated above implies that $c\left(F^{\mathrm{M}}\right)=c\left(F_{T}\right)$ for $F^{\mathrm{M}} \geq F_{T}$ (the damage associated with the event is the maximal damage) and $c\left(F^{\mathrm{M}}\right)=0$ for $F^{\mathrm{M}}<F_{T}$ (damages for smaller events are negligible).

This assumption is clearly a strong approximation. It does not take into account the fact that an increase in extreme flows would not only translate into more frequent floods of the same intensity, but also into more intense floods, affecting new areas. And if land-use plans or protection have been designed properly as a function of current floods, more intense floods could result in much higher losses, because protections fail or because floods affect new highly-populated and not-prepared areas (Hallegatte et al., 2011).

This assumption also considers no adaptation, as it assumes that vulnerability does not change, regardless of changes in flood frequency. In areas where floods become extremely frequent, it becomes unacceptable to assume that population and assets will not be adapted. In practice, new defenses will be built, or houses will not be reconstructed after a flood (strategic retreat).

With these hypotheses, damages depend only on the probability of exceeding the level $F_{T}$ and on the cost of the representative flood in the $\mathrm{SSH}$ :

$\int p\left(F^{\mathrm{M}}\right) c\left(F^{\mathrm{M}}\right) d F^{\mathrm{M}}=p_{\left(F^{\mathrm{M}} \geq F_{T}\right)} c\left(F_{T}\right)$

and climate change damages read:

$\left[\hat{p}_{\left(F^{\mathrm{M}} \geq F_{T}\right)}^{\mathrm{CC}}-\frac{1}{T}\right] c\left(F_{T}\right)$.

$F_{T}$ can be determined using the current flow series, while $\hat{p}_{\left(F^{\mathrm{M}} \geq F_{T}\right)}^{\mathrm{CC}}$ is the outcome of climate change scenarios, downscaling and statistical analysis.

\subsubsection{Assessment of current flood losses}

The cost of the reference event, $c\left(F_{T}\right)$, is determined for different types of economic units indexed by $i$. The following unit types are used: individual housing, collective housing (each unit corresponding to a household), public sector units, industry, agriculture and "artisans commerçants et prestataires de services (ACPS)" corresponding to small businesses.

The cost is calculated using the capital per unit $k_{i}$, and the number $n_{i}$ of units exposed to the reference flood in a SSH, as well as a loss ratio per unit, in case the reference flood occurs $\left(l_{i}^{F_{T}}\right)$ :

$c\left(F_{T}\right)=\sum_{i} k_{i} l_{i}^{F_{T}} n_{i}$. 
Table 1. Aggregation of capital account sectors.

\begin{tabular}{|c|c|}
\hline Housing & Activités immobilières (EM) \\
\hline Agriculture & Agriculture, sylviculture, pêche (DA) \\
\hline Public & Services administrés (DQ) \\
\hline Industry & $\begin{array}{l}\text { Industrie (DB), Construction (DH), } \\
\text { Commerce de gros, intermédiaires (FJ2), } \\
\text { Transports (EK), Activités financières (EL), } \\
\text { Services aux entreprises (EN) }\end{array}$ \\
\hline Small businesses & $\begin{array}{l}\text { Commerce et réparation automobile (FJ1), } \\
\text { Commerce de détail et réparations (FJ3), } \\
\text { Services aux particuliers (EP) }\end{array}$ \\
\hline
\end{tabular}

To determine the capital per unit, we divide the total capital for one unit type $\left(K_{i}\right)$ in France by the number of such units $\left(N_{i}\right)$. Total capital is taken from the 2603 account "Capital fixe net par branche en fin d'année à prix courants" (net fixed capital per branch at the end of the year at current prices) in 2006 for housing and 2009 for the other sectors (INSEE, 2009b). The dates are consistent with the vulnerable units data, and using current prices is also consistent with the event costs given in current prices. The date difference and inflation around those dates are small, which allows the use of current prices without much loss of precision. Table 1 shows the aggregation used for the different unit types to obtain the total capital $K_{i}$. The number of units $N_{i}$ is the total number of unit, in each unit category, over France, taken from INSEE data.

Individual and collective housing are not distinguished in the capital account $K_{\mathrm{H}}$, therefore surfaces per housing are used to split housing capital into the two categories. Surfaces per housing are taken from INSEE data "taille et peuplement des résidences principales en France métropolitaine" (size and population of place of residence in mainland France) with $S_{\text {coll }}^{\mathrm{M}}=66 \mathrm{~m}^{2}$ and $S_{\text {indiv }}^{\mathrm{M}}=111 \mathrm{~m}^{2}$. Total number of housing in mainland and overseas territories of France $N_{\text {coll }}^{\mathrm{M}+\mathrm{O}}$ and $N_{\text {indiv }}^{\mathrm{M}+\mathrm{O}}$ come from INSEE too "Répartition des logements selon leur catégorie et le type de logement" (proportion of residences by category and type) in 2006 . $k_{\text {coll }}$, the capital per collective housing unit, is then given by:

$k_{\mathrm{coll}}=\frac{K_{H}}{N_{\text {coll }}^{\mathrm{M}+\mathrm{O}}} \frac{N_{\text {coll }}^{\mathrm{M}} S_{\text {coll }}^{\mathrm{M}}}{N_{\text {coll }}^{\mathrm{M}} S_{\text {coll }}^{\mathrm{M}}+N_{\text {indiv }}^{\mathrm{M}} S_{\text {indiv }}^{\mathrm{M}}}$.

Instead of using water depth as in te Linde et al. (2011) and Feyen et al. (2012), loss ratios for each type of capital are considered to be homogeneous over the territory. Two data sources are used to assess the loss ratios for a reference event, $l_{i}^{F_{T}}$ : (i) figures compiled by the French Ministry of Environment (Grislain-Letrémy and Peinturier, 2010) (MEDD); and (ii) the report from the "Fédération des assurances" (FFSA) on the Var flooding in June 2010 (FFSA and GEMA, 2011a). Two other simpler scenarios are considered, one with $15 \%$
Table 2. Loss ratio (losses in percent of capital per unit), using three loss-ratio assumptions: the Ministry of the Environment report (MEDD), and the FFSA report on the Var flood (Var) and the Xynthia event (Xynthia).

\begin{tabular}{lrrrrr}
\hline Type & MEDD & Var & Xynthia & $15 \%$ & $30 \%$ \\
\hline Individual & 7 & 14 & 25 & 15 & 30 \\
Collective & 7 & 14 & 25 & 15 & 30 \\
Agriculture & 12 & 43 & 23 & 15 & 30 \\
Industry & 2 & 9 & 3 & 15 & 30 \\
Public & 2 & 7 & 4 & 15 & 30 \\
Small businesses & 25 & 47 & 48 & 15 & 30 \\
\hline
\end{tabular}

loss for every type of unit and one with $30 \%$. In the following, the loss ratio for the unit type $i$ and the loss-ratio assumption $e$ is noted $l_{i}^{e}$ and the different possibilities are shown in Table 2.

Losses are computed for another event, the Xynthia storm of February 2010, based on the FFSA report (FFSA and GEMA, 2011b). For Xynthia, an extra-tropical storm that affected the Atlantic coastline of France and lead to large floods, the losses reported in the "Système des catastrophes naturelles" (Cat-Nat), the government system that manages some catastrophic events, are assumed to correspond to the flood losses ${ }^{2}$. The Xynthia event is not a river flood event, but losses largely arose from submersion and - as the protection levels and activities on the shores and river banks are similar - this case also gives an interesting data point that can be used for comparison. However, the losses corresponding to that event are not used further in the assessments, as this event is not a river flood event.

For Xynthia floods and the Var floods, damages to cars are affected by housing or industries, based on the number of claims. For the Var floods, it is also possible to determine separately damages to agricultural units and small businesses. For the public sector the mean cost per claim for businesses is used.

The number of units affected by a reference event in the considered SSH, $n_{i}$, is set to the estimated number of units $i$ in the flood-prone areas of the SSH. This estimation is achieved by intersecting data on building and settlements locations with areas at risk, aggregated on the SSHs.

Locations of housing come from the 2006 census database at the IRIS level (INSEE, 2006), while businesses and public units geocoded addresses are from the SIRENE database (INSEE, 2009a). Areas at risk are taken from the "Atlas de Zone Inondable (AZI)", through the Cartorisque maps (Ministère de l'Écologie, du Développement durable, des Transports et du Logement, 2009). The number of units is aggregated on the SSHs. These data have been produced by the

\footnotetext{
${ }^{2}$ Wind losses are not covered by the Cat-Nat system.
} 


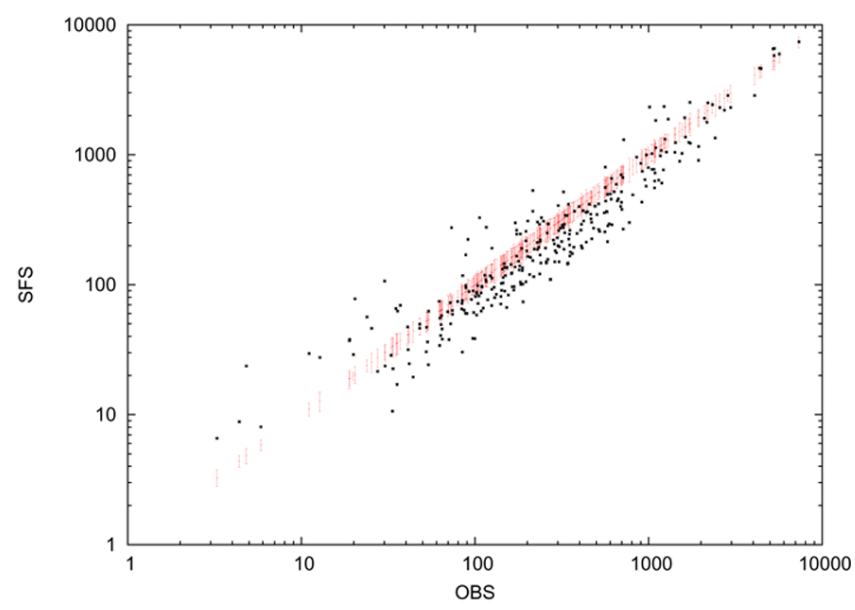

Fig. 1. Return level of SFS against observations OBS, for a ten-year return level on a log-log scale. The error bars correspond to the $95 \%$ confidence interval for the observations.

"Mission des sociétés d'assurance pour la connaissance et la prévention des risques naturels"3.

\subsection{Flood losses under climate change}

The 100-yr flood is used as the reference flood. Flood damage changes are only evaluated on sub-catchments (SSH) where there is at least one station with river flow data. If there is more than one station in an SSH, the stations are supposed to be uniformly distributed over the $\mathrm{SSH}$, and the average probability is used.

Costs are then aggregated over a wider area, the "secteur hydrographique" (SH) (catchment basin) to avoid giving too much importance to specific stations or SSHs.

Formally, indexing catchments SH with $c$, sub-catchments SSH with $s$, stations in sub-catchments with $j$, noting $N_{s}^{S}$ the number of stations in sub-catchment $s, G^{s}$ the set of stations in sub-catchment $s, S^{c}$ the set of sub-catchments in catchment $c$ and $\Phi$ the set of sub-catchments with at least one station, one gets for the cost of climate change on catchment $c, \Delta C^{c, e}$ :

$\Delta C^{c, e}=\sum_{s \in S^{c} \cap \Phi}\left(\frac{1}{N_{s}^{S}} \sum_{j \in G^{s}} p_{\left(F^{M} \geq F_{T}^{j}\right)}^{\mathrm{CC}, j}-\frac{1}{T}\right) \sum_{i} k_{i} n_{i}^{s} l_{i}^{e}$.

The cost of flooding without climate change on the areas with stations is:

$C_{0}^{c, e}=\sum_{s \in S^{c} \cap \Phi} \frac{1}{T} \sum_{i} k_{i} n_{i}^{s} l_{i}^{e}$.

\footnotetext{
${ }^{3}$ http://www.mrn.asso.fr/
}

\section{Validation and results}

\subsection{Validation under current climate}

To validate the models and assess their capacity to reproduce current climate observations, two comparisons are of interest: (i) to validate the hydrological model, it is useful to compare the river-flow reference scenario SFS (i.e., the flow calculated by SIM from the weather observations) against river flow observations ${ }^{4}$; (ii) to validate the climate modeling and downscaling, it is useful to compare the river-flow scenarios QMS and WTS calculated by SIM from downscaled climate simulations, using 50-yr (1961-2011) for the statistical analysis, against the reference scenario SFS which spans 38-yr (1970-2007).

Table 3 shows those comparisons, by noting the percentage of stations with a return level below, within or above the $95 \%$ confidence interval of the reference return period, for return periods of 10,50 and 100-yr. The reference simulation SFS underestimate extreme events, a fact already noted in Habets et al. (2008). This suggests that the hydrological model is not perfectly able to reproduce such extreme events. The QMS and WTS simulation are in the $95 \%$ confidence interval of the reference simulation for at least $40 \%$ of the stations.

To assess the dispersion of the points outside of the $95 \%$ confidence interval, the return levels of SFS are plotted against observation in Fig. 1. WTS and QMS are plotted against SFS on Fig. 2 for a 10-yr return period on a log-log scale.

As already mentioned, SFS has difficulties reproducing extremes. The two downscaling techniques, however, behave reasonably well, and the extremes reproduced by the QMS and WTS simulations are close to the SFS ones. Overall, the reproduction of the flood extremes by the hydrological simulation is not very satisfying, while the two downscaling techniques are acceptable.

Maps showing confidence intervals for the observations compared with the return levels for SFS, WTS and QMS, for all the stations are displayed in the Supplement. Stations with return level below or above the $95 \%$ confidence interval seem to be clustered, while stations inside the $95 \%$ confidence interval are dispersed over the studied area.

Similar illustrations of the GEV performance are given in the Supplement, showing that the performance is similar to the Gumbel distribution performance described here.

\footnotetext{
${ }^{4}$ This comparison uses river flow observations from the Ministère de l'Ecologie et du Développement Durable, Direction de l'Eau MEDD/DE (2009), selecting only stations with more than $35 \mathrm{yr}$ of data.
} 

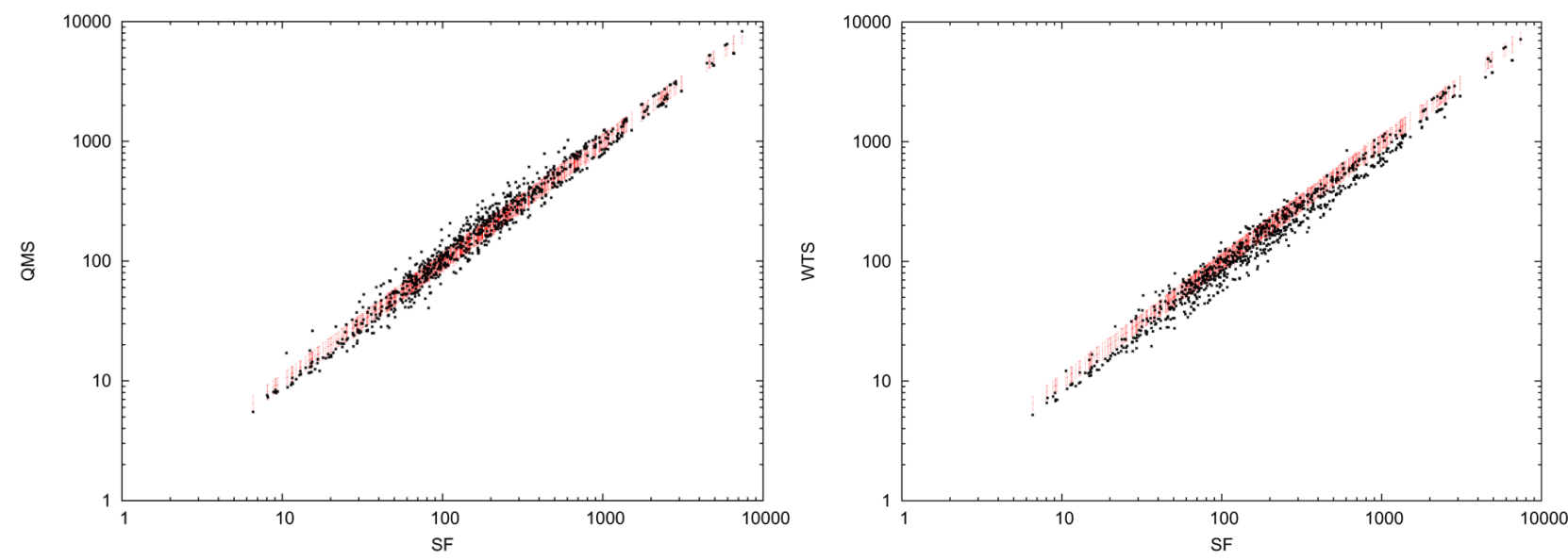

Fig. 2. Return levels of QMS and WTS against SFS, for a ten-year return level on a log-log scale. The error bars correspond to the $95 \%$ confidence interval for the SFS return levels.

Table 3. Number of stations with a return level below $(<)$, in the $95 \%$ confidence interval (in), or above ( $>$ ), for different return periods and different simulations compared to references (OBS is the reference for SFS, SFS is the reference for QMS and WTS).

\begin{tabular}{lccccccccc}
\hline Return periods & \multicolumn{3}{c}{$10-\mathrm{yr}$} & \multicolumn{3}{c}{$50-\mathrm{yr}$} & \multicolumn{3}{c}{$100-\mathrm{yr}$} \\
& $<$ & in & $>$ & $<$ & in & $>$ & $<$ & in & $>$ \\
\hline SFS vs. OBS & 59.4 & 22.9 & 17.7 & 59 & 24.2 & 16.5 & 58.6 & 25.2 & 16.2 \\
QMS vs. SFS & 22.8 & 51.8 & 25.4 & 17.1 & 56.3 & 26.6 & 15.9 & 57.5 & 26.6 \\
WTS vs. SFS & 50.5 & 42.8 & 6.8 & 43.2 & 48.6 & 8.2 & 40 & 50.5 & 9.6 \\
\hline
\end{tabular}

\subsection{Impact of climate change on flood return periods}

To assess the impact of climate change on floods, we start with an investigation of the effect of climate change on return periods.

To do so, we start from the return level $F_{T}$ calculated with the current climate for the return period $T$, and we estimate the probability of exceeding this return level in the climate change simulations QMS and WTS, and we compare it with $1 / T$.

Figure 3 shows the return period - over the 2035-2064 period and using the QMS scenario - of the return level that corresponds to a 100-yr return period over the 1970-1999 period. This map shows that, in this scenario, there are large fractions of the French territory in which what is a $100-\mathrm{yr}$ event today becomes a less than 40-yr event. In other terms, the likelihood of the current 100 -yr event is multiplied by more than 2 in many locations, as soon as 2050. In other subcatchments, however, the probabilities are largely reduced, showing that the impact of climate change on flood frequencies obtained here is heterogeneous within a given region with sub-catchments with increasing and decreasing flood frequencies. The patterns of this changes are coherent with precipitation patterns changes derived by the two downscaling methods, as shown by Quintana Seguí et al. (2011).
Similarly, Fig. 4 shows the return period - over the 20352064 period and using the WTS scenario - of the return level that corresponds to a 100 -yr return period over the 1970 1999 period. This map shows the same type of patterns, with a large heterogeneity and large increases and decreases in flood frequencies.

Comparison of those maps show that both downscaling techniques agree on the lower Rhone basin, the Hérault basin and the Cévennes and Causses region for an increase of flood frequencies. They also agree on decreasing flood frequencies over the upstream Garonne and the sub-catchments east of the Massif Central. But the two downscaling techniques disagree on the Seine basin, Brittany, and eastern France.

The Supplement includes the same maps for the two future time periods, 2035-2064 and 2069-2098, for the 10-yr return period event (instead of the 100-yr event), with 40-yr (instead of 30-yr) time periods, and with a GEV distribution instead of a Gumbel distribution. With a 10 -yr reference return period event, the location of the frequency changes are broadly conserved, but changes are less important and the contrast between the two downscaling techniques are less pronounced. Using a 40-yr duration changes the results for some stations, however the general picture remains the same. Lastly, when a GEV is used instead of a Gumbel, results are modified, sometime over whole sub-basins and changes in probabilities are more important than with a Gumbel. The overall picture of 


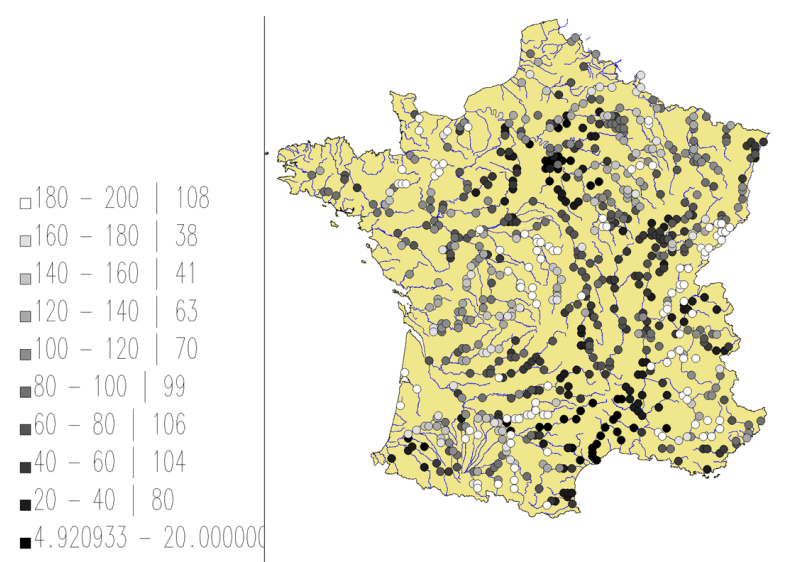

Fig. 3. Return period under climate change associated with the present time 100-yr return period level. The downscaling technique is QM and the future time period is 2035-2064. Increases in return period above doubling (e.g. the probability is divided by more than 2 ) are figured as doubling. The map is built using GRASS (GRASSGIS, 2008).

time and space patterns remains about the same, suggesting that our results are robust to these changes.

However, the two downscaling techniques give different results, with even more disagreement when using a GEV, although they both seem to be correct in present times. The sensitivity to the climate scenario - which is known to be important - and the hydrological modeling cannot be tested with our current setting.

\subsection{Climate change impact on flood losses}

Having assessed future changes in flood frequencies, we now turn to the economic valuation.

To assess our economic valuation methodology, the expected flood losses per year (from Eq. 11) are summed over the whole territory and over the sub-catchments with stations, in the five loss-ratio cases (Tab. 4). The area over which changes are computed corresponds to $70 \%$ of total damages. This expected cost over France can be compared with the estimation done by the insurance sector in FFSA (2009), which is around 0.865 billion Euro per year. This figure is quite similar with the expected costs evaluated in our study, although methodologies are completely different. It is difficult to propose a real validation, since the floods over the last 30-yr the period during which economic data on flood losses exist - cannot be considered as representative of flood risks in France; for instance, no major flood of the Seine, the Loire or the Garonne occurred during this period.

Figures 5 shows the expected annual flood losses today, using loss ratios based on the Var event flood. Using a different assumption for the loss ratio leads to different levels of losses, but the geographical pattern is very similar (see Supplement).

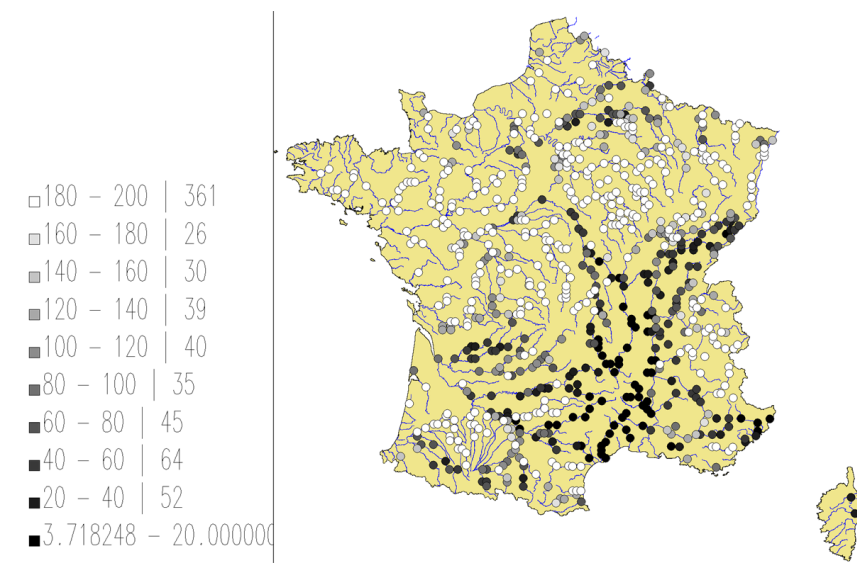

Fig. 4. Return period under climate change associated with the present time 100-yr return period level. The downscaling technique is WT and the future time period is 2035-2064. Increases in return period above doubling (e.g. the probability is divided by more than 2) are figured as doubling.

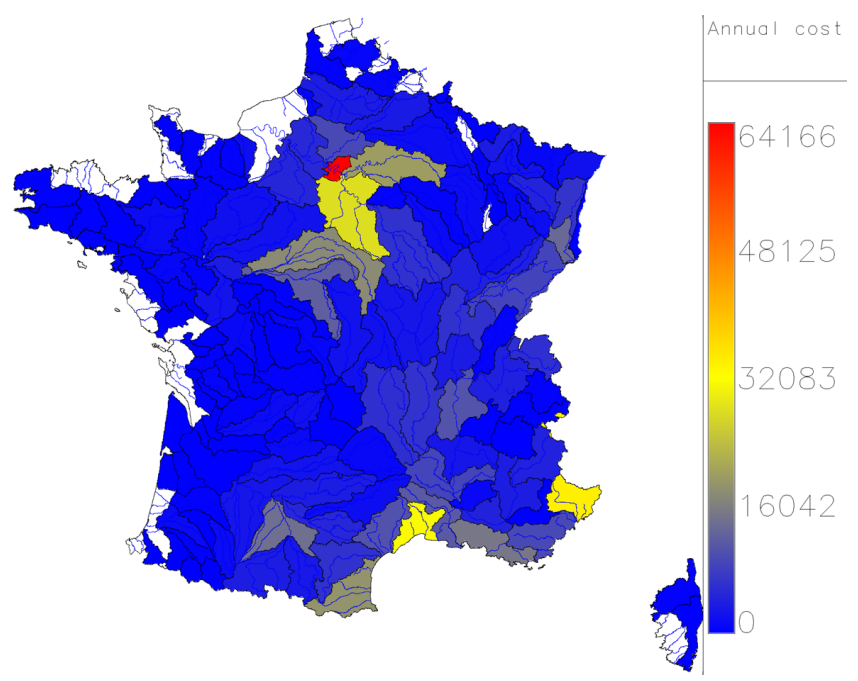

Fig. 5. The color of the areas correspond to the current expected annual losses, indicating the importance of each area. The loss-ratio assumption is based on the Var event losses.

Figures 6 and 7 show the relative change in flood losses due to climate change $\left(\Delta C^{c, e} / C_{0}^{c, e}\right)$, assuming loss ratios based on the Var event flood. They use the QM and the WT downscaling, respectively. The differences between the two downscaling techniques previously seen for return periods are also clearly visible when looking at flood losses. However, changes in flood losses exhibit a spatial consistency that reflects the evolution of climate as determined by the climate model and the downscaling methods. If a GEV distribution is used for the statistical analysis, the extreme events increase is much higher, while keeping similar geographical patterns. More maps with the different cases presented above are available in the Supplement. 

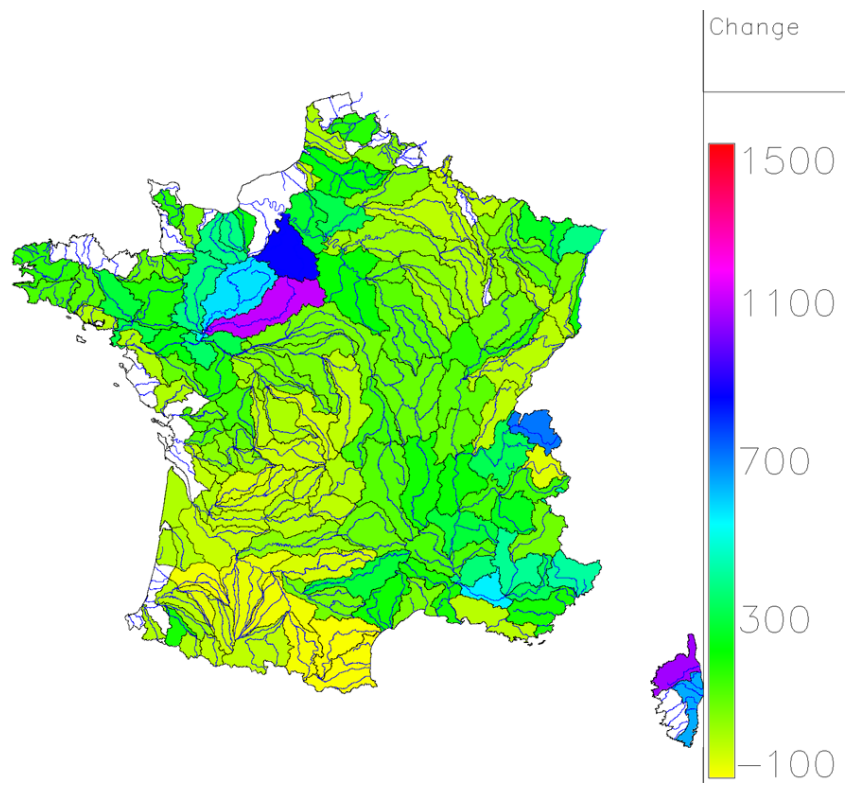

Fig. 6. The color of the areas correspond to changes in flood losses, in percent. The result presented here correspond to QMS scenario, comparing costs in 1970-1999 and 2069-2098; the loss-ratio assumption is based on the Var event losses.

Table 5 shows the aggregated future flood losses in France according to our analysis, with the different assumptions for the loss-ratio. It shows that the assumption made on the loss ratio has almost no influence on the assessment of the climate change relative impacts. Geographical patterns are also unchanged.

In every cases, there is an overall increase of losses. However the timing and amplitude depends on the distribution used and the downscaling technique.

If a Gumbel distribution is used for the statistical analysis, the resulting increases are significant in the near term, although in 2075 with the WTS scenario, the increase is only $19 \%$, while it reaches $131 \%$ in 2050 . When a GEV is used, aggregated losses are found to increase significantly in the two scenarios, with at least a doubling as soon as 2050.

In spite of the uncertainties that have been discussed in this article, these results suggest that flood losses may increase in the country in response to climate change. Socio-economic trends may worsen the situation by increasing the population and assets at risks.

Although the cost is quite different when using a Gumbel or a GEV, the geographical pattern of cost change is similar in 2050 and 2075. The statistical distribution used to determine the change of probability is therefore of importance for the magnitude of the changes for the 100-yr event, even if the geographical pattern is more influenced by the downscaling methodology.

It is also interesting to note that, with a GEV and the WT downscaling technique, total losses increase over the coun-

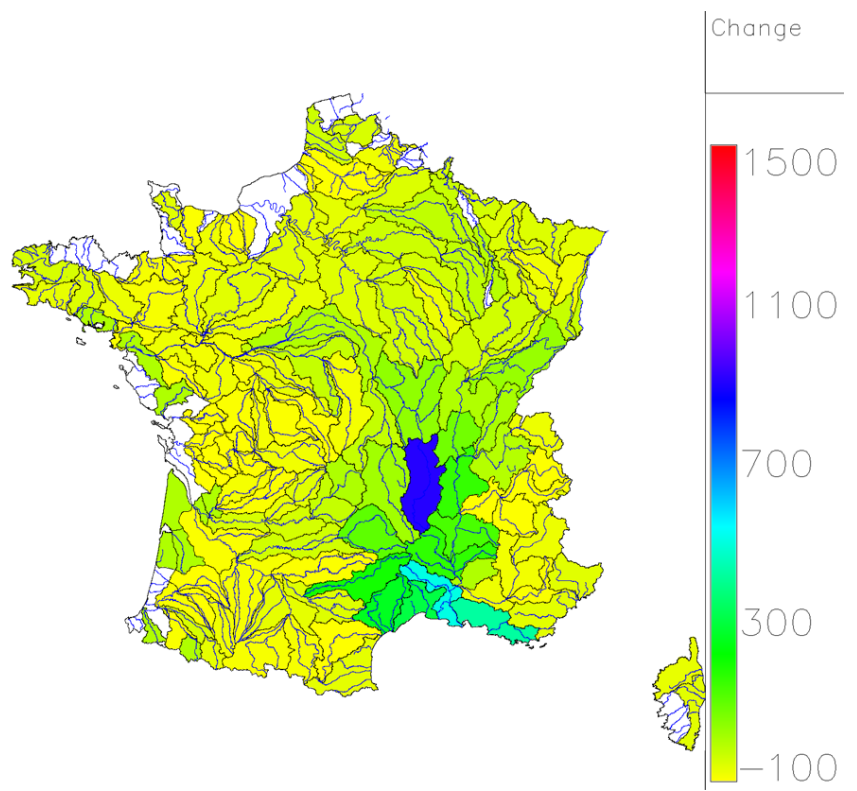

Fig. 7. The color of the areas correspond to changes in flood losses, in percent. The result presented here correspond to WTS scenario, comparing costs in 1970-1999 and 2069-2098; the loss-ratio assumption is based on the Var event losses.

try, while flood risks decrease in a majority of locations. This is due to the fact that, even though flood losses are almost canceled in many locations, an increase of more than $400 \%$ are relatively common in other places, leading to an increase in aggregated losses. In such a situation, future flood risks may become more concentrated in "flood vulnerability hot spots." The QM downscaling technique provides a very different picture, with risks that increase more homogeneously in the country, at least with a GEV. If a Gumbel distribution is used for the statistical analysis, the locations of changes are still very different depending on the the downscaling technique used, but the types of patterns are more similar.

Comparing estimated flood losses in 2050 and 2075 for the Gumbel distribution or the GEV and the WTS scenario, it is interesting to note that there is a doubling between now and 2050, and a stability or even decrease between 2050 and 2075, while average temperature keeps rising for the whole century. Three explanations can be proposed. It is possible that the extreme in streamflows reacts nonlinearly with temperature change, with most of the increase occurring for limited temperature changes. A second possibility is that the relationship between streamflow and economic losses is nonlinear. A last possibility - and by far the most plausible one (Allen and Ingram, 2002) - is that the time profile may be explained by the natural variability of the most extreme precipitation events, which is over-imposed on the trend due to climate change, something already noted, for example, in Feyen et al. (2012). This complex dynamic suggests that an assessment of future flood losses would require accounting 
Table 4. Expected costs of floods on Mainland France and on the sub-catchments with stations, in billion Euro. The 100-yr return period event is taken as a reference event.

\begin{tabular}{lrrrr}
\hline Event & MEDD & Var & $15 \%$ & $30 \%$ \\
\hline Cost France & 0.331 & 0.749 & 0.780 & 1.562 \\
Cost study & 0.229 & 0.518 & 0.540 & 1.080 \\
\hline
\end{tabular}

explicitly for natural climate variability. Doing so would require an ensemble-based approach, i.e. a large set of runs using the same climate model. Using only one simulation of a model could lead to an over-interpretation of the results, taking run-dependent natural variability trends as robust anthropogenic climate change trends.

\section{Conclusions}

This study investigates the influence of climate change on flood losses over mainland France, using state of the art climatological simulations and downscaling techniques, as well as a very simple methodology to estimate economic losses. Looking only at relative changes removes the effect of very uncertain elements of the methodology, including hydrological modeling issues, and the lack of exhaustive data on losses over France for historical and potential floods.

Even though the proposed methodology is very simple and does not account for many factors, it provides a useful estimate of how changes in extreme flows may translate into changes in economic losses. Our results suggest that a large increase in aggregated flood losses in France are possible by the middle of this century, although this is not the only possible outcome. Population change and economic growth could amplify this trend (Hallegatte, 2011), while appropriate adaptation actions could mitigate it.

Some crucial uncertainties remains, however, and it is impossible to provide a reliable projection of flood losses. There are important differences between the two downscaling techniques, weather typing and quantile mapping, especially on the geographical patterns of flood frequency change, despite the fact that both seem to be valid on the current climate. The distinction of the climate signal from natural variability would also require additional analysis. The amplitude of the changes are also sensitive to the statistical distribution fitted on the extreme events, as a GEV used instead of a Gumbel leads to cost increases that are much more important, especially in 2075 .

Also, changes in extreme event probabilities are important in some cases. The extreme value theory and associated methodologies may perform badly when extreme events become too common, as it is often found in our analysis. Statistical biases cannot thus be ruled out.
Table 5. Expected costs of floods under climate change for different loss types, downscaling techniques and years, in billion Euros.

\begin{tabular}{lccc}
\hline Event & Year & QMS & WTS \\
\hline MEDD & 2010 & 0.230 & 0.230 \\
\cline { 2 - 4 } Gumbel & 2050 & $0.567(+146 \%)$ & $0.532(+131 \%)$ \\
& 2075 & $0.530(+130 \%)$ & $0.273(+19 \%)$ \\
\cline { 2 - 4 } GEV & 2050 & $0.768(+233 \%)$ & $0.463(+101 \%)$ \\
& 2075 & $1.327(+477 \%)$ & $0.437(+90 \%)$ \\
\hline Var & 2010 & 0.518 & 0.518 \\
\cline { 2 - 4 } Gumbel & 2050 & $1.291(+149 \%)$ & $1.217(+135 \%)$ \\
& 2075 & $1.201(+132 \%)$ & $0.624(+21 \%)$ \\
\cline { 2 - 4 } GEV & 2050 & $1.718(+231 \%)$ & $1.055(+104 \%)$ \\
& 2075 & $2.964(+472 \%)$ & $0.992(+91 \%)$ \\
\hline 15\% & 2010 & 0.539 & 0.539 \\
\cline { 2 - 4 } Gumbel & 2050 & $1.351(+151 \%)$ & $1.284(+138 \%)$ \\
& 2075 & $1.267(+135 \%)$ & $0.660(+22 \%)$ \\
\cline { 2 - 4 } GEV & 2050 & $1.745(+224 \%)$ & $1.118(+107 \%)$ \\
& 2075 & $3.030(+462 \%)$ & $1.047(+94 \%)$ \\
\hline $30 \%$ & 2010 & 1.079 & 1.079 \\
\cline { 2 - 4 } Gumbel & 2050 & $2.701(+150 \%)$ & $2.568(+138 \%)$ \\
& 2075 & $2.533(+135 \%)$ & $1.321(+22 \%)$ \\
\cline { 2 - 4 } GEV & 2050 & $3.491(+224 \%)$ & $2.235(+107 \%)$ \\
& 2075 & $6.060(+462 \%)$ & $2.094(+94 \%)$ \\
\hline \multirow{3}{*}{ Gon }
\end{tabular}

Finally, our economic analysis based on a single reference flood is extremely simple compared with the complexity of flood modeling. The fact that larger river flows may lead to the inundation of new areas and to additional damage with deeper water levels is not taken into account. A systematic investigation of the bias introduced by the methodology, for example using the Feyen et al. (2012) methodology, would be useful to assess the robustness of our results.

Overall, it seems that predicting, at the catchment level, the change in vulnerability to flooding under climate change is still out of reach. Possible futures with similar plausibility give very different outcomes, making it impossible to provide robust results. But local planners need to be aware that future local changes in flood losses may be important, with noticeable reductions and increases, depending on the area.

Anticipated adaptation would be easier if uncertainty could be reduced over the short term. But natural variability will make it difficult to do so, by making it difficult to discriminate among models and to validate them.

But it does not mean that no policy action is possible. First, reactive adaptation measures, for instance withdrawals in flood aftermaths, could be able to mitigate the increase in flood losses. Also, "no regret" flood-mitigation measures that would make sense in the current climate may be able to reduce future flood losses (Hallegatte, 2009). For instance, 
stricter application of existing regulation - e.g., the "Plan de Prévention des Risques d'Inondation" that ban new construction in flood-prone areas - could be a reasonable first step toward climate change adaptation. Including climate change information in new versions of these plans could even improve their efficiency, for instance by enlarging flood-prone areas where models project a large increase in extreme river flows. However, the large uncertainty in future flood risks calls for the use of more than one climate and hydrological model to assess how flood risks may change in future.

Finally, our results also reinforce the idea that adapting to climate change will not be easy because of uncertainty on future local climates. These difficulties need to be included in assessments of climate change consequences that are used to inform policies on greenhouse gas emission reductions (Hourcade et al., 2009).

\section{Supplementary material related to this article is available online at: http://www.nat-hazards-earth-syst-sci.net/13/809/2013/ nhess-13-809-2013-supplement.pdf.}

Acknowledgements. This work was financed by the MEDUP project: "Forecast and projection in climate scenario of Mediterranean intense events: Uncertainties and Propagation on environment", of the ANR-VMC2007 program (Grant ANR07-VULN-06-001) of the French National Research Agency. We would like to thank the MRN, "Mission des sociétés d'assurance pour la connaissance et la prévention des risques naturels" for the data on exposure over France, with special thanks going to Roland Nussbaum, Jérôme Chemitte and Chadi Hajji.

Edited by: M.-C. Llasat

Reviewed by: two anonymous referees

\section{References}

Allen, M. R. and Ingram, W. J.: Constraints on future changes in climate and the hydrologic cycle, Nature, 419, 224-232, doi:10.1038/nature01092, 2002.

Barredo, J. I.: Normalised flood losses in Europe: 1970-2006, Nat. Hazards Earth Syst. Sci., 9, 97-104, doi:10.5194/nhess-9-972009, 2009.

Boé, J. and Terray, L.: A Weather-Type Approach to Analyzing Winter Precipitation in France: Twentieth-Century Trends and the Role of Anthropogenic Forcing, J. Climate, 21, 3118, doi:10.1175/2007JCLI1796.1, 2008.

Boone, A., Calvet, J. C., and Noilhan, J.: Inclusion of a Third Soil Layer in a Land Surface Scheme Using the Force-Restore Method, J. Appl. Meteorol., 38, 1611-1630, 1999.

Boé, J., Terray, L., Habets, F., and Martin, E.: A simple statistical-dynamical downscaling scheme based on weather types and conditional resampling, J. Geophys. Res., 111, 1-20, doi:10.1029/2005JD006889, 2006.
Déqué, M.: Frequency of precipitation and temperature extremes over France in an anthropogenic scenario: Model results and statistical correction according to observed values, Global Planet. Change, 57, 16-26, doi:10.1016/j.gloplacha.2006.11.030, 2007.

Durand, Y., Brun, E., Merindol, L., Guyomarc'h, G., Lesaffre, B., and Martin, E.: A meteorological estimation of relevant parameters for snow models, Ann. Glaciol., 18, 65-71, 1993.

Feyen, L., Dankers, R., Bódis, K., Salamon, P., and Barredo, J.: Fluvial flood risk in Europe in present and future climates, Clim. Change, 112, 47-62, doi:10.1007/s10584-011-0339-7, 2012.

FFSA: Synthèse de l'étude relative à l'impact du changement climatique et de l'aménagement du territoire sur la survenance d'événements naturels en France, Tech. rep., Fédération française des sociétés d'assurances,

http://www.ffsa.fr/sites/upload/docs/application/pdf/2010-05/ synthese_etude_changement_climatique.pdf, 2009.

FFSA and GEMA: Inondations du Var des 15 et 16 juin 2010 Bilan chiffré au 31 mai 2011, Tech. rep., Fédération française des sociétés d'assurances, Groupement des entreprises mutuelles d'assurances, http://www.ffsa.fr, 2011a.

FFSA and GEMA: La tempête Xynthia du 28 février 2010 - Bilan chiffré au 31 décembre 2010, Tech. rep., Fédération française des sociétés d'assurances, Groupement des entreprises mutuelles d'assurances, http://www.ffsa.fr/sites/upload/docs/application/ pdf/2011-06/bilanxynthia28022011.pdf, 2011b.

Gibelin, A. L. and Déqué, M.: Anthropogenic climate change over the Mediterranean region simulated by a global variable resolution model, Clim. Dynam., 20, 327-339, doi:10.1007/s00382002-0277-1, 2003.

GRASS-GIS: GRASS Development Team, Geographic Resources Analysis Support System (GRASS) Software, Open Source Geospatial Foundation Project, http://grass.osgeo.org, 2008.

Grislain-Letrémy, C. and Peinturier, C.: Le régime d'assurance des catastrophes naturelles en France métropolitaine entre 1995 et 2006, Le Point sur, 1-4, http://www.developpement-durable. gouv.fr/IMG/pdf/LPS54.pdf, 2010.

Habets, F., Boone, A., Champeaux, J.-L., Etchevers, P., Franchisteguy, L., Leblois, E., Ledoux, E., Le Moigne, P., Martin, E., Morel, S., Noilhan, J., Quintana Seguí, P., Rousset Regimbeau, F., and Viennot, P.: The SAFRAN-ISBA-MODCOU hydrometeorological model applied over France, J. Geophys. Res., 113, DO6113, doi:10.1029/2007JD008548, 2008.

Hallegatte, S.: Strategies to adapt to an uncertain climate change, Global Environ. Change, 19, 240-247, doi:10.1016/j.gloenvcha.2008.12.003, 2009.

Hallegatte, S.: How economic growth and rational decisions can make disaster losses grow faster than wealth, Policy Research Working Paper Series 5617, The World Bank, 2011.

Hallegatte, S., Ranger, N., Mestre, O., Dumas, P., Corfee Morlot, J., Herweijer, C., and Wood, R.: Assessing climate change impacts, sea level rise and storm surge risk in port cities: a case study on Copenhagen, Clim. Change, 104, 113-137, doi:10.1007/s10584010-9978-3, 2011.

Hourcade, J.-C., Ambrosi, P., and Dumas, P.: Beyond the Stern Review: Lessons from a risky venture at the limits of the cost-benefit analysis, Ecol. Econ., 68, 2479-2484, doi:10.1016/j.ecolecon.2009.04.011, 2009.

INSEE: Résultats du recensement de la population, http://www. recensement-2006.insee.fr/home.action, 2006. 
INSEE: SIRENE (R) base de données, La base de données des entreprises et des établissements, http://www.sirene.fr/, 2009a.

INSEE: Comptes nationaux - Base 2000, Insee, http://www.insee. $\mathrm{fr} / \mathrm{fr} /$ indicateurs/cnat_annu/archives/comptes_annee_2009.zip, 2009b.

Katz, R. W., Parlange, M. B., and Naveau, P.: Statistics of extremes in hydrology, Adv. Water Resour., 25, 1287-1304, 2002.

Kleinen, T. and Petschel-Held, G.: Integrated assessment of changes in flooding probabilities due to climate change, Clim. Change, 81, 283-312, 2007.

Ledoux, E., Girard, G., de Marsilly, G., and Deschenes, J.: Spatially distributed modeling: conceptual approach, coupling surface water and ground water., in: Unsaturated Flow Hydrologic Modeling-theory and Practice, Kluwer Academic, Dordrecht, 435-454, 1989.

MEDD and IGN: BD CarTHAgE, http://www.sandre.eaufrance.fr/ Version-2009-de-la-BDCarthage,

http://services.sandre.eaufrance.fr/

data/zonage/Hydrographie2009/

LicencenoncommercialeBDCARTHAGEConventionMEDD_ IGNn9229.pdf, 2009.

Ministère de l'Écologie, du Développement durable, des Transports et du Logement: Cartorisque, http://cartorisque.prim.net/, (last access: 2009), 2009.

Ministère de l'Ecologie et du Développement Durable, Direction de l'Eau MEDD/DE: HYDRO, www.hydro.eaufrance.fr (last acces: 2009), 2009.

Nakićenović, N. and Swart, R.,: Special Report on Emissions Scenarios, Cambridge University Press, http://www.ipcc.ch/ ipccreports/sres/emission/, 2000.

Noilhan, J. and Mahfouf, J.: The ISBA land surface parameterisation scheme, Global Planet. Change, 13, 145-159, 1996.

Noilhan, J. and Planton, S.: A Simple Parameterization of Land Surface Processes for Meteorological Models, Mon. Weather Rev., 117, 536-549, 1989.

Pagé, C., Terray, L., and Boé, J.: dsclim: A software package to downscale climate scenarios at regional scale using a weather-typing based statistical methodology, Tech. rep., Climate Modelling and Global Change - CERFACS, Toulouse, http://www.cerfacs.fr/globc/publication/technicalreport/2009/ dsclim_doc.pdf, 2009.

Planton, S., Déqué, M., Chauvin, F., and Terray, L.: Expected impacts of climate change on extreme climate events, C. R. Geosci., 340, 564-574, doi:10.1016/j.crte.2008.07.009, 2008.

Prudhomme, C. and Davies, H.: Assessing uncertainties in climate change impact analyses on the river flow regimes in the UK, part 1: baseline climate, Clim. Change, 93, 177-195, doi:10.1007/s10584-008-9464-3, 2009a.
Prudhomme, C. and Davies, H.: Assessing uncertainties in climate change impact analyses on the river flow regimes in the UK, part 2: future climate, Clim. Change, 93, 197-222, doi:10.1007/s10584-008-9461-6, 2009b.

Quintana-Seguí, P., Le Moigne, P., Durand, Y., Martin, E., Habets, F., Baillon, M., Canellas, C., Franchisteguy, L., and Morel, S.: Analysis of Near-Surface Atmospheric Variables: Validation of the SAFRAN Analysis over France, J. Appl. Meteorol. Clim., 47, 92-107, doi:10.1175/2007JAMC1636.1, 2008.

Quintana Seguí, P., Martin, E., Habets, F., and Noilhan, J.: Improvement, calibration and validation of a distributed hydrological model over France, Hydrol. Earth Syst. Sci., 13, 163-181, doi:10.5194/hess-13-163-2009, 2009.

Quintana Seguí, P., Ribes, A., Martin, E., Habets, F., and Boé, J.: Comparison of three downscaling methods in simulating the impact of climate change on the hydrology of Mediterranean basins, J. Hydrol., 383, 111-124, doi:10.1016/j.jhydrol.2009.09.050, 2010.

Quintana-Seguí, P., Habets, F., and Martin, E.: Comparison of past and future Mediterranean high and low extremes of precipitation and river flow projected using different statistical downscaling methods, Nat. Hazards Earth Syst. Sci., 11, 1411-1432, doi:10.5194/nhess-11-1411-2011, 2011.

Somot, S., Sevault, F., and Déqué, M.: Transient climate change scenario simulation of the Mediterranean Sea for the twenty-first century using a high-resolution ocean circulation model, Clim. Dynam., 27, 851-879, doi:10.1007/s00382-006-0167-z, 2006.

Somot, S., Sevault, F., Déqué, M., and Crépon, M.: 21st century climate change scenario for the Mediterranean using a coupled Atmosphere-Ocean Regional Climate Model, Global Planet. Change, 63, 112-126, doi:10.1016/j.gloplacha.2007.10.003, 2008.

Stephenson, A. and Gilleland, E.: Software for the Analysis of Extreme Events: The Current State and Future Directions, Extremes, 8, 87-109, 2005.

te Linde, A. H., Bubeck, P., Dekkers, J. E. C., de Moel, H., and Aerts, J. C. J. H.: Future flood risk estimates along the river Rhine, Nat. Hazards Earth Syst. Sci., 11, 459-473, doi:10.5194/nhess-11-459-2011, 2011.

Vidal, J.-P., Martin, E., Franchistéguy, L., Baillon, M., and Soubeyroux, J.-M.: A 50-year high-resolution atmospheric reanalysis over France with the Safran system, Int. J. Climatol., 30, 16271644, doi:10.1002/joc.2003, 2010.

Wood, A. W., Leung, L. R., Sridhar, V., and Lettenmaier, D. P.: Hydrologic Implications of Dynamical and Statistical Approaches to Downscaling Climate Model Outputs, Clim. Change, 62, 189216, doi:10.1023/B:CLIM.0000013685.99609.9e, 2004. 